\title{
Transient Performance Enhancement of Tank Circuited 3-Pole PV Based DC Microgrid with Limit-Based P \& O MPPT Algorithm
}

\author{
Babatunde A. Giwa \\ School of Engineering \\ University of Greenwich (UoG) \\ Medway, United Kingdom \\ b.a.giwa@greenwich.ac.uk
}

\author{
Yehdego Habtay \\ School of Engineering \\ University of Greenwich (UoG) \\ Medway, United Kingdom \\ Y.T.Habtay@gre.ac.uk
}

\begin{abstract}
This paper presents a limit-based approach in improving transient performance of tank-circuited 3-Pole PV Based DC Microgrid (3-PPDM) during zero to non-zero insolation transition of the solar irradiance profile. This approach is necessitated due to the transient behavior of the microgrid during the above-mentioned transition that results into huge voltage sag which appears to violate the conditions set for desirable operation of the de loads. The tank-circuited 3-PPDM is conceived to mimic, under set conditions, operational feature of grid-connected three-phase ac microgrid where transformer is not required at distribution level for the provision of different voltage levels (phase and line) operation within the ac microgrid. 3-PPDM is developed with PV Based DC Microgrid connected to ac grid via single stage de link and 3-Level Voltage Source Converter (3L-VSC). The de loads are directly connected to the de link and operated at high and low voltage levels without the employment of dc-dc converters. These voltage levels are established via the support of the three poles created by two serially connected centre-tapped capacitors meant primarily for improving the harmonic performance of the 3L-VSC. The observed huge voltage sag is technically linked to abrupt change in the high de link reference voltage of the de link PI controller during zero irradiance to low voltage of the PV power optimizer at the transition point. Subsequently, a limit-based perturb and observe maximum power point tracking (P\&O MPPT) technique was employed as corrective measure. The concept of the technique is to determine the transition point and assign suitable pre-determined value that is within the technical constraint of the microgrid as the reference voltage of the dc link. The simulation results of this approach prove the efficacy of the techniques as the set conditions are successfully met within considerable time, leading to an improvement in the transient performance of the microgrid.
\end{abstract}

Keywords—Tank Circuit (TC), Limit-based P\&O MPPT, DC-link, PV, DC Microgrid, 3L-VSC; 3-Pole.

\section{INTRODUCTION}

The proliferation of worldwide public awareness in creation of friendly environment from less dependence on fossil fuelbased power generation is playing vital role in unprecedented growth in the use of renewable energy resources (RES) as new sources of power generation [1]. The technologies of RES include but not limited to geothermal, wind, solar thermal and photovoltaic (PV), biomass, hydro and fuel cells. These technologies are called RES because their input fuels such as wind, sun and landfill gas are unlimitedly in abundance and freely obtained. In addition to their unlimited input fuels, they are perceived as economical replacement for non-renewable energy sources such as diesel and natural gas power plants, due to their reduced carbon emission and enriched power quality. As the output of these RES is either dc or ac [2] that must be converted to dc for operation of Modern Technological Systems (MTS) such as dc machines, data centres and Adjustable Frequency Drives (AFDs), these MTS could form a cluster if operated concurrently from these sources. Operation of these MTS in cluster form represents dc microgrid [3] where the MTS denote the dc loads that are either directly powered by RES or via dc-dc converter depending on the required operating dc voltage level.

In spite of numerous benefits of RES, the issue of reliability and availability of power from RES would arise if a number of RES are not adequately aggregated or supported by energy storage elements such as battery, flywheel and supercapacitor $[1,4]$. This is due to intermittent nature of most RES as their input fuels are not readily available throughout the day. A typical example is the solar irradiance level, it is only appreciable during the day to obtain appreciable power from the solar PV. Another problem of some of the RES is their nonintelligent nature that result to them not been able to optimise their output power. This has also resulted to poor efficiency of 
some RES systems. For example, the embodiment of Maximum Power Point Tracking (MPPT) algorithm in the solar PV system has helped to increase the efficiency of the PV system by ensuring that the operating voltage of the PV correspond to the maximum power point voltage (Vmpp). Among the MPPT techniques, Perturb and Observe MPPT (P\&O MPPT) algorithm is popularly used due to its cost effectiveness and simplicity. Many studies [5-9] have been carried out with employment of different versions of P\&O MPPT techniques in the areas of efficiency improvement and reliability enhancement of PV system connected to either loads or main grid via power electronics devices such as ac-dc converter and dc-dc converter at low voltage operation. In [5], modified $\mathrm{P} \& \mathrm{O}$ MPPT techniques was proposed where sampling oscillation around the maximum power point (MPP) was avoided by monitoring changes in irradiance during partial shaded conditions. This technique shows an improvement in the overall performance of the PV system. The modified P \& O MPPT technique employed in [6] was applied in 3-pole PVbased DC microgrid (3-PPDM) where dc loads are operated at different voltage levels without the use of dc-dc converters. This technique was used to assign pre-determined reference voltage for the dc link PI controller during zero irradiance. With this, the dc link voltage is kept within the set limit. However, the deficiency of the technique in [6] is its inability to detect zero to non-zero transition point of the solar irradiance profile which could lead to violation of the set limit for the dc link voltage. Grey Wolf-based P \& O MPPT algorithm was employed in [7] to mitigate the undermining effect of swift variation of insolation and partial shading on the power optimisation of PV. However, in [8], the version of P \& O MPPT algorithm employed as PV power optimser was based on self-predictive and decisive. This version is employed to strengthen the weaknesses of some modified P \& O MPPT algorithms used in various solar PV systems. Uniqueness of this concept is that three sequential points instead of two are identified on the power-voltage curve of the PV, and then used for determination of maximum power point (MPP). This method is said to be quick enough in enhancing dynamic performance of PV system. In [9], sensorless-based MPPT together with P \& O MPPT are used for maximising power output of faulty PV system. While the sensorless MPPT detects any line to line and line to ground faults, the P \& O MPPT identifies the maximum power point on the power-voltage curve of the PV under the faulty condition. These coordinated MPPTs are said to be applicable under partial shading conditions as well. The modified P \& O MPPT algorithm studied in [6] cannot be said to be efficient if its applicability in a system such as 3-PPDM is undesirable to obvious characteristic of a day solar irradiance profile.

This paper proposes a simple and effective method of desirably operating distributed dc loads within set conditions in 3-Pole PV based DC Microgrid during zero to non-zero solar irradiance transitional period. The proposed method will employ a limit-based concept in P\&O MPPT algorithm to prevent the distributed dc loads from operational violation of their set conditions. Albeit the algorithm serves as power optimizer for the PV, the transitional event during operation of the microgrid such as change in solar insolation has necessitated the need to ephemerally alter the purpose of the algorithm for shortest possible time. This is to ensure desirable transient performance of the microgrid.

\section{SUMMARY OF TANK-CIRCUITED 3-POLE DC MICROGRID}

This section has presented the compendium, as detailed in [11] of how 3-Pole PV-Based DC Microgrid is modeled, operated and controlled to ensure that the set conditions for its desirable performance are met.

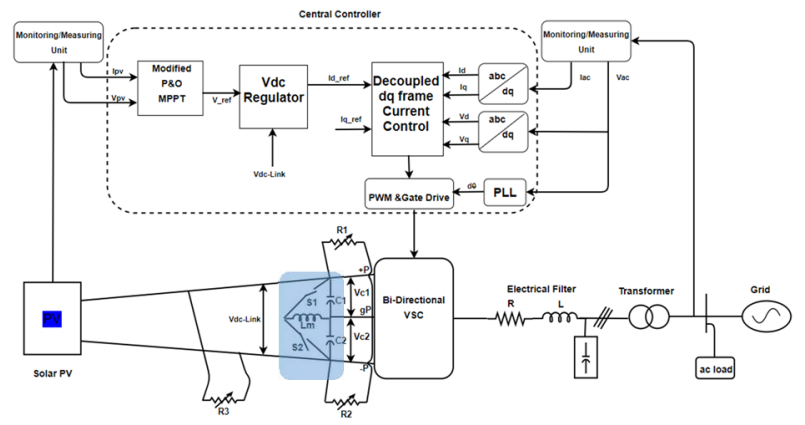

Fig 1. Architectural Design of Tank-Circuited 3-Pole PV-Based DC Microgrid

The developed model shown in fig. 1 is a low voltage PV based DC Microgrid connected to the grid through a single stage dc link and bi-directional 3L-VSC. The PV is modelled with parallel and series configuration of solar modules and inputted with solar irradiance profile in figure 2 . This profile is obtained from the database of solar weather station on April 29, 2019 at University of Greenwich Research Wolfson Centre where number of panels (SunPower SPR-415E-WHT-D) are installed. Information about the PV model is shown in table 1. From the parameters shown in table, the maximum power $\left(P V_{-} P_{m p p}\right)$ and voltage $\left(P V_{-} V_{m p p}\right)$ of the PV model at maximum power point at $1000 \mathrm{~W} / \mathrm{m}^{2}$ as defined by (1) and (2) are $256 \mathrm{~kW}$ and $510 \mathrm{~V}$ respectively.

$$
\begin{aligned}
& \text { PV_P } P_{m p p}=M_{s} \times V_{m p p} \times I_{m p p} \times M_{p} \\
& P V_{-} V_{m p p}=M_{s} \times V_{m p p}
\end{aligned}
$$

Table 1. PV Model Data

\begin{tabular}{|l|l|}
\hline \multicolumn{2}{|c|}{ Solar PV-Modules Array Parameters } \\
\hline No of modules in Series $(\mathrm{Ms})$ & 7 \\
\hline No of modules in parallel $(\mathrm{Mp})$ & 88 \\
\hline Max. power of module at $1000 \mathrm{~W} / \mathrm{m}^{2}$ & $414.8 \mathrm{~W}$ \\
\hline Open circuit voltage Voc & $85.3 \mathrm{~V}$ \\
\hline Voltage at max. power point $\left(\mathrm{V}_{\mathrm{mpp}}\right)$ at $1000 \mathrm{~W} / \mathrm{m}^{2}$ & $72.9 \mathrm{~V}$ \\
\hline Current at max. power $\left(\mathrm{I}_{\mathrm{mpp}}\right)$ at $1000 \mathrm{~W} / \mathrm{m}^{2}$ & $5.69 \mathrm{~A}$ \\
\hline
\end{tabular}

The feature of the dc link is such that it creates a platform via serially connected centre-tapped capacitors ( 11 \& $\mathrm{C} 2)$ for 
direct operation of distributed flexible dc loads (R1, R2 \& R3) at different voltage levels (Vdc_link, $\mathrm{Vc} 1$ and $\mathrm{Vc}$ ). The dc side of 3L-VSC, has got three poles $(+\mathrm{P}, \mathrm{gP}$ and $-\mathrm{P})$ together with the centre-tapped capacitors for establishment of high and low voltage operation of the dc loads without the employment of dc-dc converters. The $3 \mathrm{~L}-\mathrm{VSC}$ can be operated in both rectification and inversion modes depending on the power differential between PV output (Ppv) and total dc load demand $\left(\mathrm{P}_{123}\right)$. The conditions for rectification and inversion mode of operation of 3L-VSC are respectively in (3) and (4).

$\mathrm{PV}_{\mathrm{pv}}>\mathrm{P}_{123} \rightarrow$ Inversion mode

$\mathrm{PV}_{\mathrm{pv}}<\mathrm{P}_{123} \rightarrow$ Rectification mode

In $[7,11]$, the condition for desirable operation of $3 \mathrm{~L}-\mathrm{VSC}$ is stated in (5) while that of the dc loads (R1-R3) are stated in (6)-(8), this desirable operation is achieved with the employment of modified Perturb \& Observe Maximum Power Point Tracking (P\&O-MPPT) technique and distributed pulse width modulation (d-PWM) controlled tank circuit. The nominal voltages for operation of R1, R2 and R3 are denoted respectively with Vc1n, Vc2n and Vdc_linkn. Their numerical values are $250 \mathrm{~V}, 250 \mathrm{~V}$ and $500 \mathrm{~V}$ respectively. The highlighted part of the model in figure 1 which is the tank-circuit comprises of the two capacitors, switches S1 and S2, and inductor Lm. They are used in fulfilling the condition in (5) when R1 is not equal to R2. More details about the microgrid could be found in [10]

$\mathrm{Vc} 1 \approx \mathrm{Vc} 2 \approx \frac{\mathrm{Vdc} \_ \text {link }}{2} \approx \frac{\mathrm{Vc} 1+\mathrm{Vc} 2}{2}$

$0.94 \mathrm{Vc} 1 \mathrm{n} \leq \mathrm{Vc} 1 \leq 1.1 \mathrm{Vc} 1 \mathrm{n} \quad \rightarrow \mathrm{R} 1$

$0.94 \mathrm{Vc} 2 \mathrm{n} \leq \mathrm{Vc} 2 \leq 1.1 \mathrm{Vc} 2 \mathrm{n} \quad \rightarrow \mathrm{R} 2$

0.94Vdc_linkn $\leq$ Vdc_link $\leq$ 1.1Vdc_linkn $\rightarrow$ R3 (8)

III. Simulation AND Results of TANK-CIRCUITEd 3Pole PV-BASED DC MiCROGRID

The model in figure 1 was simulated in MATLAB/Simulink with distributed flexible dc loads $(\mathrm{R} 1=5 \Omega, \mathrm{R} 2=8 \Omega$ and $\mathrm{R} 3=3 \Omega$ ) over solar irradiance profile shown below.

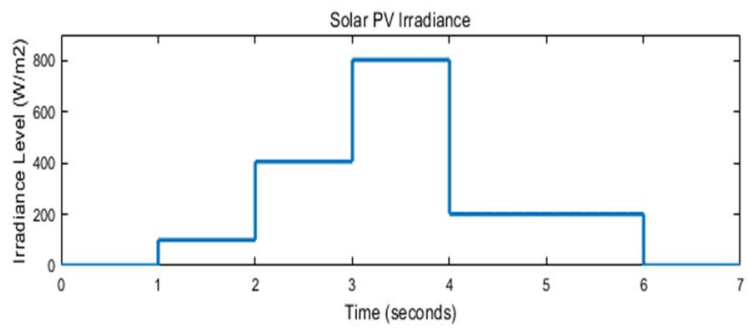

Fig. 3. Simulation Solar Irradiance Profile
The simulation is carried out using the modified and subsequently the limit-based P\&O MPPT algorithms. The irradiance profile in figure 3 is used in both cases because it is a resemblance of a day solar irradiance profile in figure 2 and secondly to reduce the required time for simulation.

\section{A. Modified P\&O MPPT Algorithm}

The model in figure 1 contains central controller for the

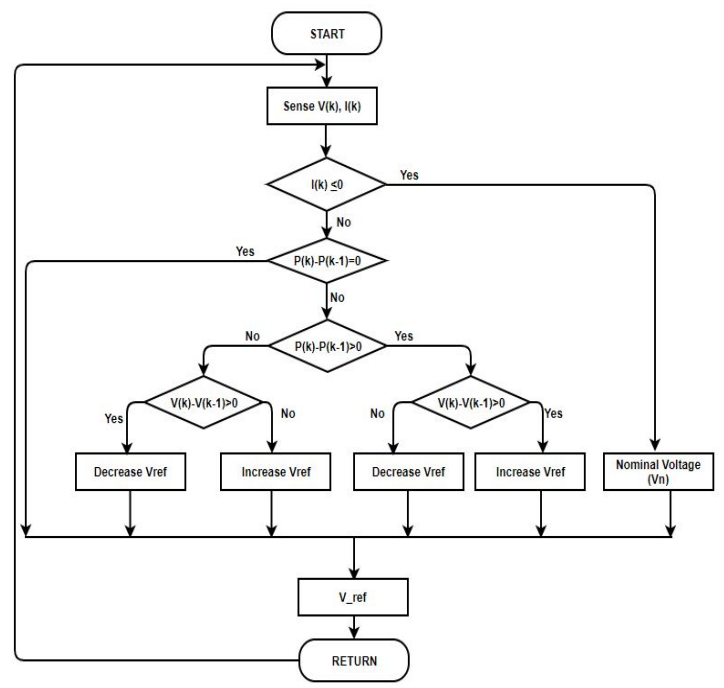

Fig. 4. Modified P\&O MPPT Algorithm for 3-PPDM

operation of the microgrid with modified $\mathrm{P} \& \mathrm{O}$ MPPT algorithm shown in figure 4 as integral part of the controller. The simulation was carried out under the load condition $(\mathrm{R} 1 \neq \mathrm{R} 2)$ to reflect flexibility of the distributed dc loads.

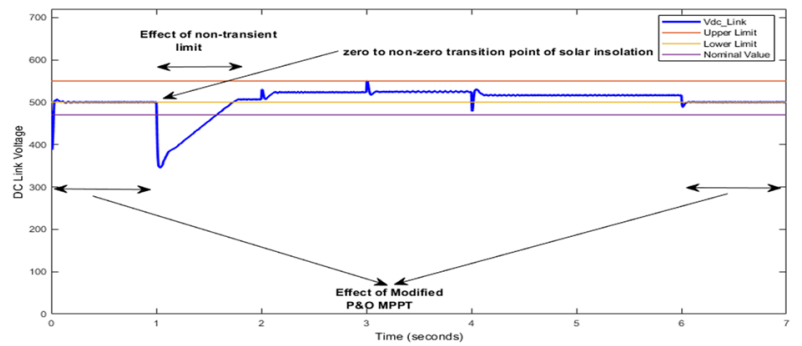

Fig. 5. Voltage Profile of R3 with Modified P\&O MPPT

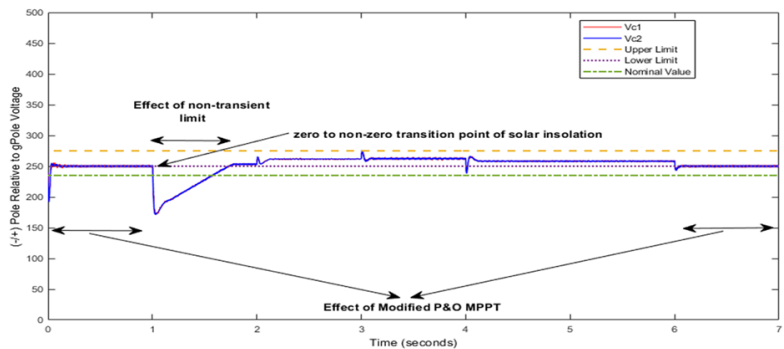

Fig. 6. Voltage Profile of R1 \& R2 with Modified P\&O MPPT 
The simulation results in figure 5 and figure 6 show occurrence of voltage sag at $1 \mathrm{sec}$ of the simulation time and lasted for 771 milliseconds. This is a violation of the operational set conditions in (6)-(8) for the dc loads and this occurs during irradiance level transition from zero to non-zero. This violation shows the weakness of the modified P\&O MPPT algorithm during the transition on the transient behaviour of 3-PPDM

\section{B. Limit-Based P\&O MPPT Algorithm}

The effect of poor efficacy of the Modified P\&O MPPT algorithm as clearly shown in the voltage profile of the dc loads in figure $5 \& 6$ was as a result of the inability of the algorithm to detect the transition point of the solar irradiance where irradiance level changes from zero to non-zero. However, the

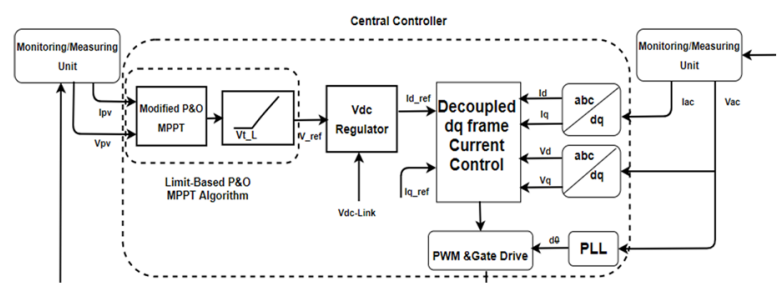

Fig. 7. Block Diagram of Redeveloped Central Controller for 3-PPDM

modified P\&O MPPT algorithm was redeveloped to hold its initial features as well as the ability to detect the transition point of the solar irradiance mentioned above.

This redeveloped algorithm employed limit- based concept for the period when the solar irradiance is zero and during the identified transition point in figure 5. In view of the concept employed, the redeveloped algorithm is structured into two parts as shown in the depiction of the new central controller in figure 7. They are the modified P\&O MPPT plus transient lower voltage limiter. Hence, the name 'limit-based P\&O MPPT algorithm' and this is explicitly depicted in figure 8 .

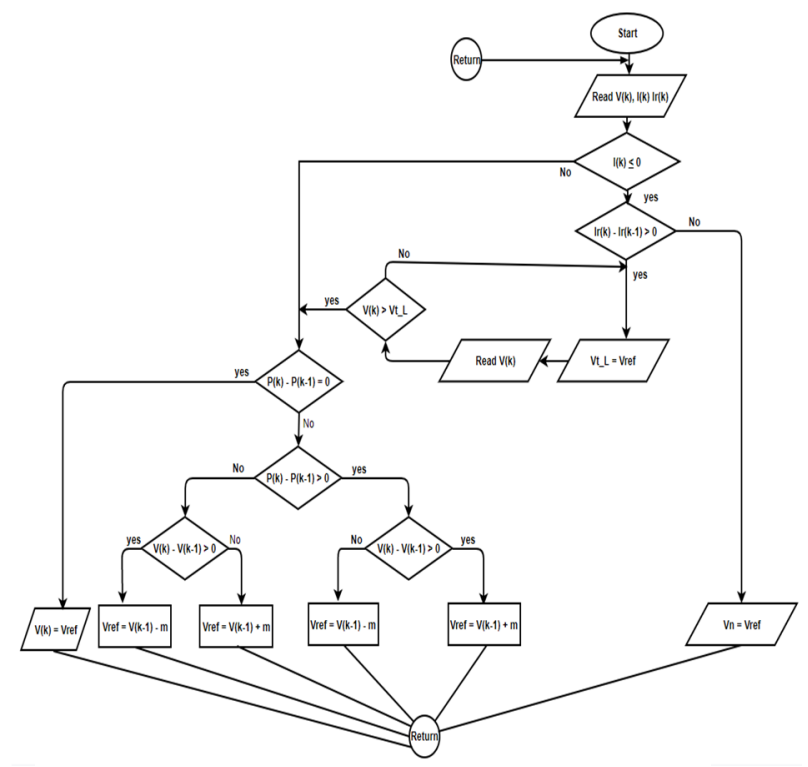

Fig. 8. Limit-Based P\&O MPPT Algorithm

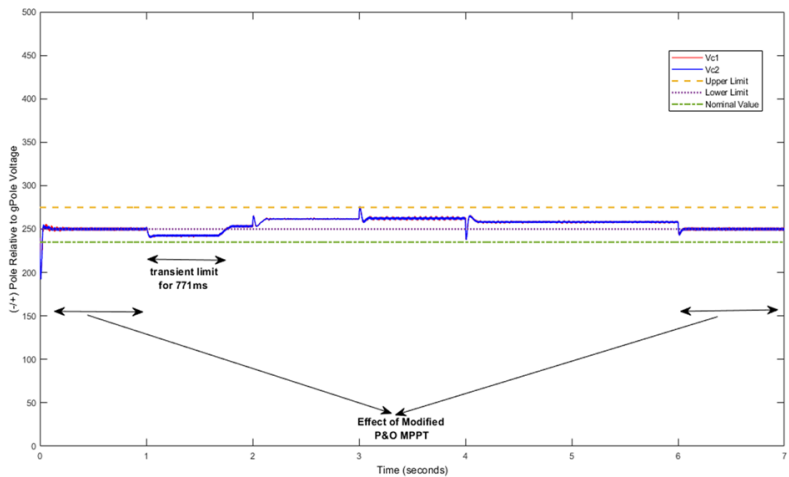

Fig. 9. Voltages of R1 \& R2 with Limit-Based P\&O MPPT Algorithm

This algorithm uses three parameters such as irradiance level (Ir), voltage and current of the PV $(\mathrm{V}(\mathrm{k})$ and $\mathrm{I}(\mathrm{k}))$ for optimizing the power output of the PV and ensuring that the set conditions in (6)-(8) are met. Vn is the nominal voltage for R3 and at the same as reference voltage (V_ref or Vref) of the dc link PI controller when the solar irradiance is zero. The PI

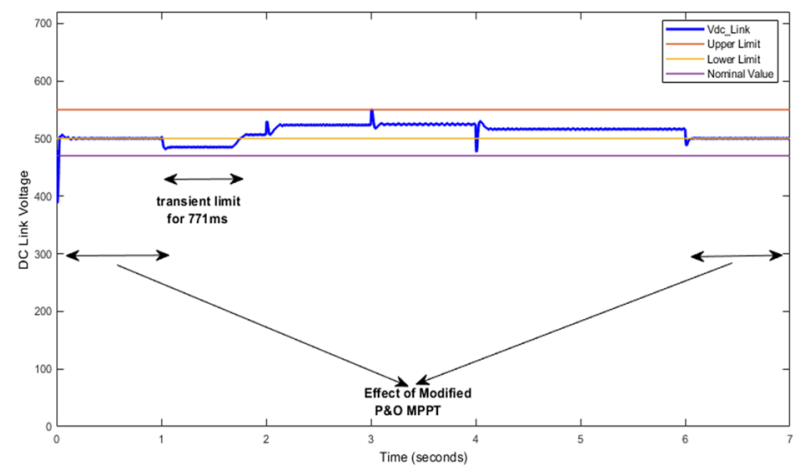

Fig. 10. Voltage Profile of R3 with Limit-Based P\&O MPPT Algorithm

controller is the Vdc regulator shown in figure 7 and it regulates the dc link voltage by providing corresponding current (Id_ref) of the Vref as its output command. Vt_L is the limit voltage and the reference voltage (Vref) of the dc link PI controller during the transition point sited above. Vref is to remain equal to $\mathrm{Vt}_{-} \mathrm{L}$ until $\mathrm{V}(\mathrm{k})$ is greater than $\mathrm{Vt} \_\mathrm{L}$. The results of the simulation with the algorithm in figure 8 is shown in figure 9 and 10. Comparatively analysis of the results obtained from the two algorithms is done in next section.

\section{DISCUSSION OF RESULTS}

Investigation revealed that the violation of the set conditions in (6)-(8) by the huge voltage sag as observed in both the dc link voltage across R3 (see figure 5) and voltage across R1 \& R2 (see figure 6) is technically linked to abrupt change in the high reference voltage of the dc link PI controller (Vdc Regulator) during zero irradiance $(500 \mathrm{~V})$ to low voltage of the PV power optimizer at the transition point. The low voltage of the PV power optimizer at this point corresponds to $\left(M_{s} \times V_{m p p}\right)$ of the PV just above zero irradiance. This is identified as less than $350 \mathrm{~V}$ in the power-voltage curve of the 
PV shown in figure 10. This is the point at which the PV is about to start generating electricity while the $3 \mathrm{~L}-\mathrm{VSC}$ is

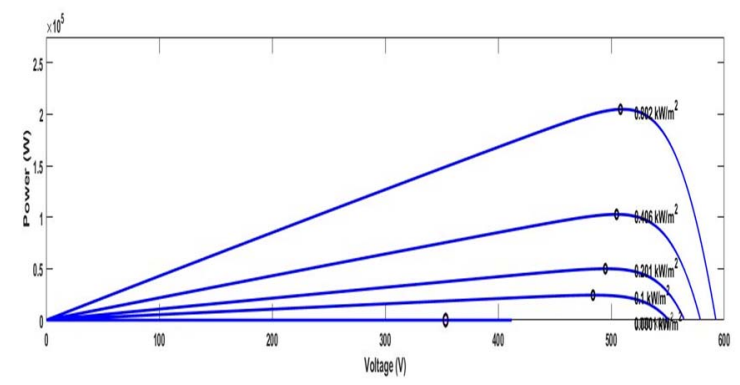

Fig. 10. MPPT Power-Voltage Characteristics of the PV

operating in rectification mode, hence, $3 \mathrm{~L}-\mathrm{VSC}$ is serving as a power source to the dc loads and operating at voltage level (V_ref) which is equivalent to $500 \mathrm{~V}$. Since the PV is in parallel connection with the $3 \mathrm{~L}-\mathrm{VSC}$ while starting to generate power at transition point, intuitively, voltage drop would be experienced. This voltage sag would continue, and the dc loads operation will remain undesirable until the PV voltage rises just above the lower voltage limit of the set condition in (8).

However, the results of the simulations with modified P\&O MPPT algorithm for desirable operation of the distributed dc loads (R1-R3) shown in figure $5 \& 6$ and that of the proposed one (limit-based P\&O MPPT algorithm) in figure $9 \& 10$ have clearly shown that the latter is an improved version of the former. This improvement is owing to the ability of the proposed algorithm to detect the transition point of the irradiance level from zero to non-zero. At the point of detection, $\mathrm{Vt}$ _L is assigned as V_ref for the shortest possible time. In this case, it is about 771 milliseconds and it is after this time that the voltage of the PV rises above Vt_L, and continuous sampling of PV voltage for maximum power point tracking is re-initiated. More so, the carefully chosen numerical value of $\mathrm{Vt} \_\mathrm{L}(485 \mathrm{~V})$ which is made to be greater than the lower limit $(0.94 \mathrm{Vdc}$ linkn) of the set condition in (8) is an added feature of the proposed algorithm.

\section{CONCLUSION}

This paper has presented a novel limit-based P\&O MPPT algorithm as an integral part of central controller in 3-Pole PVBased DC Microgrid for desirable operation of distributed dc loads within the microgrid. The novelty of this algorithm is the ability to act as corrective measure after detecting zero to non- zero transition point of the solar irradiance level. Before now, non-detection of this transition point has resulted to violation of the set conditions for desirable operation of distributed dc loads in 3-PPDM. The efficacy of this algorithm was visible in simulations results for 771 milliseconds as it proves comparatively better than previous approach. This has led to enhancement of the transient performance of the 3-PPDM during the transition point.

The future work of this research will be to study the level of distortion of the PV power optimization during the transition point in question. This is to establish and quantify power loss in form of un-optimised power of the PV if there is any.

\section{REFERENCES}

[1] H. Nehrir et al., "A review of hybrid renewable/alternative energy systems for electric power generation: Configurations, control and applications," 2012 IEEE Power and Energy Society General Meeting, San Diego, CA, 2012, pp. 1-1.

[2] D. S. G. Krishna and M. Patra, "Modeling of multi-phase DC-DC converter with a compensator for better voltage regulation in DC microgrid application," 2016 International Conference on Signal Processing, Communication, Power and Embedded System (SCOPES), Paralakhemundi, 2016, pp. 989-994.

[3] D. Salomonsson and A. Sannino, "Low-Voltage DC Distribution System for Commercial Power Systems With Sensitive Electronic Loads," in IEEE Transactions on Power Delivery, vol. 22, no. 3, pp. 1620-1627, July 2007

[4] S. Skarvelis-Kazakos, B. A. Giwa and D. Hall, "Microgrid power balancing with redox flow batteries," IEEE PES Innovative Smart Grid Technologies, Europe, Istanbul, 2014, pp. 1-6.

[5] C. Hua and Y. Chen, "Modified perturb and observe MPPT with zero oscillation in steady-state for PV systems under partial shaded conditions," 2017 IEEE Conference on Energy Conversion (CENCON), Kuala Lumpur, 2017, pp. 5-9.

[6] B. A. Giwa and Y. Habtay, "Multi-Voltage Level Operation of DC Loads in 3-Pole PV-Based DC Microgrid," unpublished

[7] S. Mohanty, B. Subudhi and P. K. Ray, "A Grey Wolf-Assisted Perturb \& Observe MPPT Algorithm for a PV System," in IEEE Transactions on Energy Conversion, vol. 32, no. 1, pp. 340-347, March 2017

[8] N. Kumar, I. Hussain, B. Singh and B. K. Panigrahi, "Framework of Maximum Power Extraction From Solar PV Panel Using Self Predictive Perturb and Observe Algorithm," in IEEE Transactions on Sustainable Energy, vol. 9, no. 2, pp. 895-903, April 2018.

[9] D. S. Pillai and N. Rajasekar, "An MPPT-Based Sensorless Line-Line and Line-Ground Fault Detection Technique for PV Systems," in IEEE Transactions on Power Electronics, vol. 34, no. 9, pp. 8646-8659, Sept. 2019

[10] B. A. Giwa and Y. Habtay, "Tank circuiting of 3-pole PV-based dc microgrid for pole-to-pole voltage balancing, in press. 